Int. J. Electrochem. Sci., 14 (2019) 2965 - 2983

\title{
Solution Combustion Synthesis of Lithium Cobalt Oxide - Cathode Material for Lithium-Ion Batteries
}

\author{
VictorD. Zhuravlev ${ }^{1}$, Anna V. Shikhovtseva ${ }^{2}$, Larisa.V. Ermakoval, ElizavetaYu. Evshchik ${ }^{2, *}$, \\ Elena A. Sherstobitova ${ }^{3}$, Dmitry V. Novikov ${ }^{4}$, Olga V. Bushkova ${ }^{1,2,3}$, Yuri A. Dobrovolsky ${ }^{2}$ \\ ${ }^{1}$ Institute of Solid State Chemistry, Ural Branch of the Russian Academy of Sciences, Ekaterinburg \\ 620990, Russia \\ ${ }^{2}$ Institute of Problems of Chemical Physics, Russian Academy of Sciences, Chernogolovka 142432, \\ Moscow Region, Russia \\ ${ }^{3}$ M.N. Mikheev Institute of Metal Physics, Ural Branch of the Russian Academy of Sciences, \\ Ekaterinburg 620990, Russia \\ ${ }^{4}$ InenergyLlc, Moscow 115201, Russia \\ *E-mail: liza@icp.ac.ru
}

doi: $10.20964 / 2019.03 .79$

Received: 6 November 2018 / Accepted: 20 December 2018 / Published: 7 February 2019

\begin{abstract}
A simple but novel solution combustion synthesis (SCS) technique suitable for $\mathrm{LiCoO}_{2}$ scale production was developed. Citric acid was used together with glycine to slow down the combustion rate; cobalt(II) nitrate was partially replaced with cobalt(II) carbonate hydroxide to reduce the heating of the off-gases using the excess heat of the redox reaction. As a result, no open flame or eruption of the powder product out of the reactor was observed; the rapid SCS process occurring in the desired non-turbulent mode is suitable for scaling. The influence of the ratios cobalt(II) nitrate/cobalt(II) carbonate hydroxide and glycine/citric acid on the $\mathrm{LiCoO}_{2}$ powder product properties was examined along with the influence of the post-combustion annealing conditions and $\mathrm{pH}$ of the precursor solution. The thus-obtained $\mathrm{LiCoO}_{2}$ powders were characterised by X-ray diffraction, scanning electron microscopy and particle size distribution analysis. Testing of the electrochemical behaviour of the $\mathrm{LiCoO}_{2}$ powders was performed in $\mathrm{Li} / \mathrm{LiCoO}_{2}$ test cells having $1 \mathrm{M} \mathrm{LiDFOB}$ in EC/DMC (1:1, wt.) as an electrolyte. The results confirmed the high electrochemical activity of the SCS-derived $\mathrm{LiCoO}_{2}$ powders; the best samples exhibited a discharge capacity $\geq 150 \mathrm{mAh} \mathrm{g}^{-1}$ and coulombic efficiency $\geq 99.5 \%$ following 30 cycles at $\mathrm{C} / 10$ rate.
\end{abstract}

Keywords:lithium-ion batteries; lithium cobalt oxide; solution combustion synthesis.

\section{$\underline{\text { FULL TEXT }}$}


(C) 2019 The Authors. Published by ESG (www.electrochemsci.org). This article is an open access article distributed under the terms and conditions of the Creative Commons Attribution license (http://creativecommons.org/licenses/by/4.0/). 